\title{
Chemical Syntheses of the Conducting Material Formed by Heteropolyacids and Polyaniline
}

\author{
Jian GoNG, Rui-Nian HUA, Zhong-Wei XIE, Shou-Guo WANG, and Lun-Yu QU ${ }^{\dagger}$ \\ Department of Chemistry, Northeast Normal University, Changchun 130024, P. R. China
}

(Received January 11, 2000; Accepted January 8, 2001)

\begin{abstract}
Here we report a hybrid organic-inorganic conducting material formed by vanadium-containing silicotungstic/molybdic or phosphotungstic/molybdic acid and polyaniline (PAN) with a one-step or a two-step chemical reaction involving oxidation of aniline with ammonium persulfate in the presence of vanadium-containing silicotungstic/ molybdic or phosphotungstic/molybdic acid. Polymer structure was examined by elemental analysis, IR, XRD, XPS, and thermal stability and conducting behavior was studied. Results showed that the composition and structure of main chain with one-step method were similar to that with two-step method. However, some differences in XRD spectra between the polymer with one-step and two-step methods were observed, which may be due to differences of doping methods. Conductivity of materials with a one-step method was bigger than that with a two-step method when the percentage of doping was determined. When heteropolyacid as doping agent was determinate, conductivity increased with doping percentage at the beginning and rate of conductivity was faster in the two-step method than in the one-step method. However conductivity did not increase with doping percentage when the doping percentage increased to a certain range. The conductivity of the materials descended after the materials were heated. One reason was dedoping or degradation of the materials.
\end{abstract}

KEY WORDS Polyaniline / Heteropolyacid / Hybrid Material / Conductivity /

Polyaniline (PAN) has attracted considerable attention because of its excellent environmental stability and possible technical applications as electronic material. ${ }^{1,2}$ Recently many new synthetic methods and potential applications on PAN are found. ${ }^{3-5}$ Aniline polymers have the general formula $\left[(-\mathrm{B}-\mathrm{NH}-\mathrm{B}-\mathrm{NH})_{y}(\mathrm{~B}-\mathrm{N}=\mathrm{Q}=\right.$ $\left.\mathrm{N}-)_{1-y}\right]_{x}$, where $\mathrm{B}$ represents a benzenoid ring while $\mathrm{Q}$ represents a quinonoed ring. They can be rendered conductive through appropriate oxidation or reduction. Chemically synthesized polyaniline is usually obtained in protonated form through oxidative polymerization of aniline in the presence of suitable acids. When the PAN base is doped by a protonic acid, protonation occurs at imine nitrogen sites to yield polysemiquinone, in which the polarons delocalize along the chain. ${ }^{6}$ Generally the more the protonic acid doped is, the better the conductivity of the material. ${ }^{7}$ As a strong acid, heteropoly acid (HPA) can give proton and it is possible to obtain heteropolyanion-doped polyaniline in a chemical method. ${ }^{5,8}$ M. Hasik et al. thought that the Keggin units inserted in conjugated polymers are bound with the matrix via quasi-ionic bonds and are molecularly dispersed. ${ }^{9}$ In this case heteropoly anions are incorporated into the polymer matrix during polymerization. Growing chains are cationic and require the presence of heteropoly anionic to preserve the neutrality of the system. This doping of the PAN base with heteropoly acid can be achieved in one-step or two-step process. As for two-step process, the conductivity behavior of material is a low threshold because the protonated phase is limited to the surface and penetration into the bulk of the polymer is difficult. $^{10}$

We selected $\left(\mathrm{NH}_{4}\right)_{2} \mathrm{~S}_{2} \mathrm{O}_{8}$ as the oxidant in the one-step method and doping was achieved via preparation of polyaniline in the presence of the vanadium-containing

${ }^{\dagger}$ To whom correspondence should be addressed. silicotungstic/molybdic or phosphotungstic/molybdic acid, the two-step method was also used for comparison. The obtained products were characterized by elemental analysis, IR, XRD, XPS, and the thermal stability. The conducting property of doped PAN was studied.

\section{EXPERIMENTAL}

\section{Reagents and Measurements}

All chemicals used were of analytical grade. The aniline used was distilled twice under vacuum. A PE2400 CHN element analyzer was used (USA). FT-IR studies were carried out on 5DX-FT-IR spectrophotometer (Nicolet) with $\mathrm{KBr}$ pellets. X-Ray powder patterns were taken on XD-3A X-Ray diffraction spectrometer with monochromatized $\mathrm{Cu}-K_{\alpha}$ radiation. XPS were recorded on X-Ray photoelectron spectrometer (Shimadzu). TG measurements were carried out on a TGA-7 thermal analyzer under a constant nitrogen flow, scanning rate was $10.0^{\circ} \mathrm{C} \mathrm{min}{ }^{-1}$. Conductivity was measured using a standard 4-probe method, disk shape samples were prepared from powders using $120 \mathrm{Mpa}$ pressure at room temperature. $^{11}$

\section{Synthesis of HPA}

$\mathrm{H}_{4} \mathrm{PVW}_{11} \mathrm{O}_{40} \cdot 9 \mathrm{H}_{2} \mathrm{O}, \mathrm{H}_{5} \mathrm{SiVW}_{11} \mathrm{O}_{40} \cdot 6 \mathrm{H}_{2} \mathrm{O}$ were prepared according to ref 12 and $\mathrm{H}_{4} \mathrm{PVMo}_{11} \mathrm{O}_{40} \cdot 7 \mathrm{H}_{2} \mathrm{O}$, $\mathrm{H}_{5} \mathrm{SiVMo}_{11} \mathrm{O}_{40} \cdot 9 \mathrm{H}_{2} \mathrm{O}$ were prepared according to ref 13 . They were all examined by using elemental analysis, and IR methods.

\section{One-Step Chemical Synthesis of the Hybrid PAN/HPA}

Freshly distilled aniline $(2 \mathrm{~mL})$ and vanadiumcontaining heteropolyacid (10 $\mathrm{mmol})$ was dissolved in $3.5 \mathrm{~mL}$ acetonitrile and yellowish complexes were formed immediately. A solution with $4 \mathrm{~g}$ of ammonium persulfate was dissolved in $5 \mathrm{~mL}$ distilled water and 
added dropwise to aniline-heteropolyacid-acetonitrile solution and stirred for $24 \mathrm{~h}$ at room temperature. It was then terminated by pouring the reaction mixture into $200 \mathrm{~mL}$ methanol which caused immediate black precipitation, then filter and the precipitate was repeatedly washed with methanol until the filtrate was colourless, then washed with distilled water several times. The powder was dried under vacuum until constant mass was reached. Yield: $\sim 71 \%$.

\section{Chemical Synthesis of the Polyemeraldine Base}

$5 \mathrm{~g} \mathrm{H}_{4} \mathrm{SiW}_{12} \mathrm{O}_{40}$ were dissolved in $30 \mathrm{~mL}$ acetonitrile. $1.3 \mathrm{~mL}$ freshly distilled aniline were added, then a solution with $2.6 \mathrm{~g}$ of ammonium persulfate was dissolved in $6 \mathrm{~mL}$ of distilled water and added dropwise to above mixture, stirred for $24 \mathrm{~h}$ at room temperature, and terminated by pouring the reaction mixture into $125 \mathrm{~mL}$ methanol which caused immediate black precipitation, then filter, the precipitate was repeatedly washed with methanol until the filtrate was colourless. The precipitate was dipped for $4 \mathrm{~h}$ in $0.5 \mathrm{~mol} \mathrm{~L}^{-1} \mathrm{NH}_{3} \mathrm{H}_{2} \mathrm{O}$, then filter, and the precipitate was washed with distilled water until the solution is neuter. Precipitate was dried under vacuum $40^{\circ} \mathrm{C}$ for $48 \mathrm{~h}$. Yield: $73 \%$. All above the yield are calculated based on the amount of aniline monomer.

\section{Two-Step Chemical Synthesis of the Hybrid PAN/HPA}

Vanadium-containing heteropolyacid $(1.68 \mathrm{mmol})$ was dissolved in $25 \mathrm{~mL}$ distilled water, $0.5 \mathrm{~g}$ polyemeraldine base was added, stirred for $24 \mathrm{~h}$ at room temperature, then filter, the precipitate was washed with distilled water until $\mathrm{pH}$ of the filtrate was 7 . The powder was dried under vacuum until constant mass was reached. Yield: $\sim 86 \%$. Yield was calculated based on the amount of polyaniline base.

\section{RESULTS AND DISCUSSION}

\section{Elemental Analysis}

According to results of elemental analysis (Table I), we give the following empirical formula. One-step method:

$$
\begin{array}{ll}
\mathrm{S}_{1} & \left(\mathrm{C}_{6} \mathrm{H}_{4.5} \mathrm{~N}\right)_{18.2}\left(\mathrm{H}_{4} \mathrm{PVW}_{11} \mathrm{O}_{40}\right) ; \\
\mathrm{S}_{2} & \left(\mathrm{C}_{6} \mathrm{H}_{4.5} \mathrm{~N}\right)_{10.3}\left(\mathrm{H}_{5} \mathrm{SiVMo}_{11} \mathrm{O}_{40}\right) ; \\
\mathrm{S}_{3} \quad\left(\mathrm{C}_{6} \mathrm{H}_{4.5} \mathrm{~N}\right)_{12.5}\left(\mathrm{H}_{4} \mathrm{PVMo}_{11} \mathrm{O}_{40}\right) ; \\
\mathrm{S}_{4} \quad\left(\mathrm{C}_{6} \mathrm{H}_{4.5} \mathrm{~N}\right)_{9.4}\left(\mathrm{H}_{5} \mathrm{SiVW}_{11} \mathrm{O}_{40}\right) \\
\text { two-step method: } \\
\mathrm{S}_{1}{ }^{\prime} \quad\left(\mathrm{C}_{6} \mathrm{H}_{4.5} \mathrm{~N}\right)_{56}\left(\mathrm{H}_{4} \mathrm{PVW}_{11} \mathrm{O}_{40}\right) ; \\
\mathrm{S}_{2}{ }^{\prime}, & \left(\mathrm{C}_{6} \mathrm{H}_{4.5} \mathrm{~N}\right)_{45.3}\left(\mathrm{H}_{5} \mathrm{SiVMo}_{11} \mathrm{O}_{40}\right) ; \\
\mathrm{S}_{3}{ }^{\prime}, & \left(\mathrm{C}_{6} \mathrm{H}_{4.5} \mathrm{~N}\right)_{49.3}\left(\mathrm{H}_{4} \mathrm{PVMo}_{11} \mathrm{O}_{40}\right) ; \\
\mathrm{S}_{4}{ }^{\prime} \quad & \left(\mathrm{C}_{6} \mathrm{H}_{4.5} \mathrm{~N}\right)_{42.9}\left(\mathrm{H}_{5} \mathrm{SiVW}_{11} \mathrm{O}_{40}\right)
\end{array}
$$

These show that the doped percentage of HPA in the one-step was higher than that in the two-step.

\section{IR Spectra}

IR spectra of the materials in one-step and two-step methods are shown in Figure 1. All samples exhibit similar IR spectral patterns. Ring stretching of quinoid and benzenoid forms was observed at $c a .1582$ and 1492 $\mathrm{cm}^{-1}$ respectively. The bands in the range of $1200-1400$ $\mathrm{cm}^{-1}$ are $\mathrm{C}-\mathrm{N}$ stretching bands of an aromatic amine, $1380 \mathrm{~cm}^{-1}$ is $\mathrm{QBQ}$ (Q: quinoid ring, B: benzenoid ring); $1302 \mathrm{~cm}^{-1}$ is $\mathrm{QBQ}, \mathrm{QBB}$, and $\mathrm{BBB}$ and $1240 \mathrm{~cm}^{-1}$ is BBB. Compared with IR spectra of the materials with two-step method, $1380 \mathrm{~cm}^{-1}$ band of the materials with one-step method disappeared. The quinoid structure of the products with one-step method may disappear, indicating that the polyaniline molecule has been protonated. The disappearance of the band at $1162 \mathrm{~cm}^{-1}$, which is PAN base characteristic peak, ${ }^{14}$ and the appearance of the band at $1144 \mathrm{~cm}^{-1}$, which is the characteristic band of the protonated states, ${ }^{15}$ supports this point of view. Though the band at $1380 \mathrm{~cm}^{-1}$ was kept with two-step method, the disappearance of the band at $1162 \mathrm{~cm}^{-1}$ and the appearance of the band at $1144 \mathrm{~cm}^{-1}$ show that the polyaniline has been protonted in the twostep method.

One reason of the band kept at $1380 \mathrm{~cm}^{-1}$ during protonation with two-step method is that HPA, as a big molecule, is difficult to penetrate the bulk of the polyaniline, because the protonated phase is limited to the surface in solid-liquid reaction. Also vanadium-containing HPA has a stronger oxidization, the HPA oxidizes the PAN while the PAN is doped with the PAN, so the band at $1380 \mathrm{~cm}^{-1}$ was kept in the two-step method. The
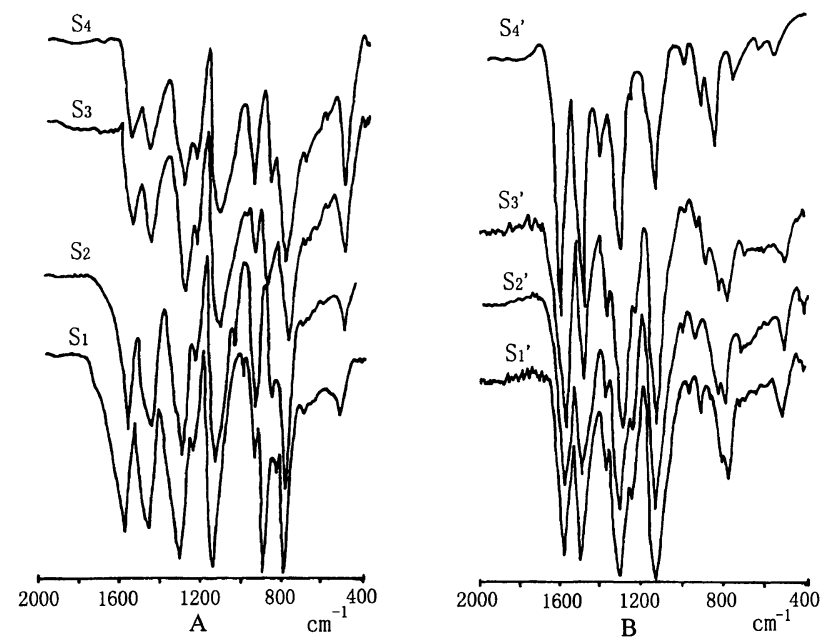

Figure 1. IR spectra of the sample in one-step (A) and two-step (B) method $\mathrm{S}_{1}\left(\mathrm{C}_{6} \mathrm{H}_{4.5} \mathrm{~N}\right)_{18.2}\left(\mathrm{H}_{4} \mathrm{PVW}_{11} \mathrm{O}_{40}\right) ; \quad \mathrm{S}_{2}\left(\mathrm{C}_{6} \mathrm{H}_{4.5} \mathrm{~N}\right)_{10.3}\left(\mathrm{H}_{5-}\right.$ $\left.\mathrm{SiVMo}_{11} \mathrm{O}_{40}\right) ; \quad \mathrm{S}_{3}\left(\mathrm{C}_{6} \mathrm{H}_{4.5} \mathrm{~N}\right)_{12.5}\left(\mathrm{H}_{4} \mathrm{PVMo}_{11} \mathrm{O}_{40}\right) ; \mathrm{S}_{4}\left(\mathrm{C}_{6} \mathrm{H}_{4.5} \mathrm{~N}\right)_{9.4}\left(\mathrm{H}_{5-}\right.$ $\left.\mathrm{SiVW}_{11} \mathrm{O}_{40}\right) ; \quad \mathrm{S}_{1}{ }^{\prime}\left(\mathrm{C}_{6} \mathrm{H}_{4.5} \mathrm{~N}\right)_{56}\left(\mathrm{H}_{4} \mathrm{PVW}_{11} \mathrm{O}_{40}\right) ; \quad \mathrm{S}_{2}{ }^{\prime}\left(\mathrm{C}_{6} \mathrm{H}_{4.5} \mathrm{~N}\right)_{45.3}\left(\mathrm{H}_{5-}\right.$ $\left.\mathrm{SiVMo}_{11} \mathrm{O}_{40}\right) ; \mathrm{S}_{3}{ }^{\prime}\left(\mathrm{C}_{6} \mathrm{H}_{4.5} \mathrm{~N}\right)_{49.3}\left(\mathrm{H}_{4} \mathrm{PVMo}_{11} \mathrm{O}_{40}\right) ; \mathrm{S}_{4}{ }^{\prime}\left(\mathrm{C}_{6} \mathrm{H}_{4.5} \mathrm{~N}\right)_{42.9}\left(\mathrm{H}_{5}-\right.$ $\mathrm{SiVW}_{11} \mathrm{O}_{40}$ ).

Table I. Elemental analysis (\%) of PAN/HPA materials

\begin{tabular}{ccccccrrrrrr}
\hline Sample & $\mathrm{C}$ & $\mathrm{H}$ & $\mathrm{N}$ & $\mathrm{W}(\mathrm{Mo})$ & $\mathrm{V}$ & $\mathrm{Sample}$ & $\mathrm{C}$ & $\mathrm{H}$ & $\mathrm{N}$ & $\mathrm{W}(\mathrm{Mo})$ & $\mathrm{V}$ \\
\hline $\mathrm{S}_{1}$ & 29.02 & 2.23 & 5.70 & 44.92 & 1.17 & $\mathrm{~S}_{1}{ }^{\prime}$ & 52.54 & 4.15 & 11.78 & 30.23 & 0.79 \\
$\mathrm{~S}_{2}$ & 27.00 & 2.31 & 5.14 & 37.39 & 1.88 & $\mathrm{~S}_{2}{ }^{\prime}$ & 47.39 & 4.11 & 9.32 & 15.86 & 0.79 \\
$\mathrm{~S}_{3}$ & 30.01 & 2.31 & 5.69 & 35.09 & 1.74 & $\mathrm{~S}_{3}{ }^{\prime}$ & 47.35 & 3.95 & 10.36 & 15.34 & 0.76 \\
$\mathrm{~S}_{4}$ & 18.35 & 1.47 & 3.61 & 55.58 & 1.47 & $\mathrm{~S}_{4}{ }^{\prime}$ & 47.40 & 3.97 & 9.61 & 32.23 & 0.83 \\
\hline
\end{tabular}


Chemical Syntheses of the Conducting Polyaniline Material

Table II. IR characteristic bands of samples

\begin{tabular}{ccccccccrcc}
\hline Sample & $\mathrm{N}=\mathrm{Q}=\mathrm{N}$ & $\mathrm{N}-\mathrm{B}-\mathrm{N}$ & & $\mathrm{C}-\mathrm{N}$ & & $\mathrm{Q}=\mathrm{NH}^{+}-\mathrm{B}$ & $v_{\text {asW(Mo)-Od }}$ & $v_{\text {asSi(P)-Oa }}$ & $v_{\text {asW(Mo)-Ob-W(Mo) }}$ & $v_{\text {asW(Mo)-Oc-W(Mo) }}$ \\
\hline $\mathrm{S}_{1}$ & 1577 & 1487 & 1301 & & 1244 & 1140 & 956 & 1068 & 880 & 799 \\
$\mathrm{~S}_{2}{ }{ }^{\prime}$ & 1577 & 1488 & 1306 & & 1245 & 1144 & 941 & 897 & 834 & 788 \\
$\mathrm{~S}_{3} \mathrm{~S}{ }^{\prime}{ }^{\prime}$ & 1577 & 1487 & 1306 & & 1245 & 1144 & 949 & 1016 & 863 & 790 \\
$\mathrm{~S}_{1}{ }^{\prime}$ & 1588 & 1477 & 1301 & & 1244 & 1136 & 949 & 903 & 880 & 790 \\
$\mathrm{~S}_{2}{ }^{\prime}$ & 1583 & 1494 & 1375 & 1312 & 1244 & 1146 & 947 & 1060 & 835 & 700 \\
$\mathrm{~S}_{3}{ }^{\prime}$ & 1580 & 1494 & 1376 & 1302 & 1244 & 1142 & 968 & 919 & 832 & 798 \\
$\mathrm{~S}_{4}{ }^{\prime}$ & 1584 & 1498 & 1379 & 1305 & 1244 & 1142 & 944 & 1010 & 834 & 800 \\
\hline
\end{tabular}

Table III. XPS $\mathrm{N}_{1 \mathrm{~S}}$ and $\mathrm{O}_{1 \mathrm{~S}}$ data of PAN/HPA materials

\begin{tabular}{|c|c|c|c|c|c|c|c|}
\hline \multirow{2}{*}{ Sample } & \multicolumn{3}{|c|}{$\mathrm{N}_{1 \mathrm{~S}}$ Binding energies/eV } & \multirow{2}{*}{$\begin{array}{c}\text { Proportion/\% } \\
\mathrm{N}^{+}\end{array}$} & \multicolumn{3}{|c|}{$\mathrm{O}_{1 \mathrm{~S}}$ Binding energies/eV } \\
\hline & $-\mathrm{N}=$ & $-\mathrm{NH}^{-}$ & $\mathrm{N}^{+}$ & & $\mathrm{O}^{2-}$ & $\mathrm{OH}^{-}$ & $\mathrm{H}_{2} \mathrm{O}$ \\
\hline $\mathrm{S}_{1}$ & 398.4 & 399.8 & 401.3 & 20.2 & 530.4 & 531.8 & 533.4 \\
\hline $\mathrm{S}_{2}$ & 398.1 & 399.4 & 401.4 & 24.5 & 530.5 & 531.7 & 533.3 \\
\hline $\mathrm{S}_{3}$ & 398.8 & 399.4 & 401.5 & 18.3 & 530.4 & 531.8 & 533.2 \\
\hline $\mathrm{S}_{4}$ & 398.4 & 399.7 & 401.3 & 24.2 & 530.4 & 531.7 & 533.2 \\
\hline $\mathrm{S}_{1}^{\prime}$ & 398.2 & 399.5 & 401.4 & 7.3 & 530.5 & 531.8 & 533.3 \\
\hline $\mathrm{S}_{2}^{\prime}$ & 398.4 & 399.8 & 401.2 & 10.7 & 530.4 & 531.7 & 533.4 \\
\hline $\mathrm{S}_{3}^{\prime \prime}$ & 398.3 & 399.8 & 401.3 & 10.5 & 530.3 & 531.9 & 533.4 \\
\hline $\mathrm{S}_{4}^{\prime}$ & 398.4 & 399.7 & 401.3 & 10.9 & 530.3 & 531.9 & 533.4 \\
\hline
\end{tabular}

bands in the spectral range between $700-1100 \mathrm{~cm}^{-1}$ corresponding to Keggin-unit structural vibrations can be distinguished easily ${ }^{16}$ (Table II). HPA protonate PAN and their identity are preserved in this process, because the IR characteristic bonds of HPA after synthesis and purification processes can be found, so we think the polyacid in products still keep its structure.

Absorption intensity of HPA in the materials by using one-step method is more than that by using two-step method. This indicates that the quantity-doped of HPA in one-step method is more than that in two-step method. Heteropolyanions are introduced to the polymer matrix and preserve structural identity during protonation.

\section{XPS Spectra}

XPS give quantitative differentiation of imine $(-\mathrm{N}=)$, amine $\left(-\mathrm{NH}^{-}\right)$and positively charged nitrogens $\left(\mathrm{N}^{+}\right)$in PAN/HPA. Deconvolution was carried out assuming in this case the same weighing of Gaussian $(75 \%)$ and Lorentzian (25\%) functions. Under these conditions the binding energy $E_{\mathrm{b}}=398.3 \mathrm{eV}$ is ascribed to the imine nitrogen $(-\mathrm{N}=)$, the binding energy $E_{\mathrm{b}}=399.4 \mathrm{eV}$ to the amine nitrogen $\left(-\mathrm{NH}^{-}\right)$, and the binding energy $E_{\mathrm{b}}=$ $401.8 \mathrm{eV}$ to the protonated nitrogens $\left(\mathrm{N}^{+}\right)$. The $\mathrm{O}_{1 \mathrm{~s}} \mathrm{XPS}$ of polyemeraldine base has two peaks. $531.1 \mathrm{eV}$ is ascribed to surface $\mathrm{OH}^{-}$anions and $533.6 \mathrm{eV}$ is ascribed to water molecules. Deconvolution of $\mathrm{O}_{1 \mathrm{~s}}$ XPS spectra of doped PAN has three peaks indicating that the sample has three different oxygen atoms. The peak whose binding energy is $530.4 \mathrm{eV}$ is ascribed to $\mathrm{O}^{2-}$ (oxygen of HPA). The binding energy $E_{\mathrm{b}}=531.1 \mathrm{eV}$ is ascribed to oxygen of $\mathrm{OH}^{-}$. The binding energy $E_{\mathrm{b}}=533.6 \mathrm{eV}$ is ascribed to oxygen of $\mathrm{H}_{2} \mathrm{O}$. The proportion of protonated nitrogen species (symbol $\mathrm{N}^{+}$) is shown in Table III. This proportion is generally viewed as indicator of doping of the individual molecules. The degree of doping corresponds to the proportion of $\mathrm{N}^{+}$in the two-step method. However, it is not completely correspond to in the one-

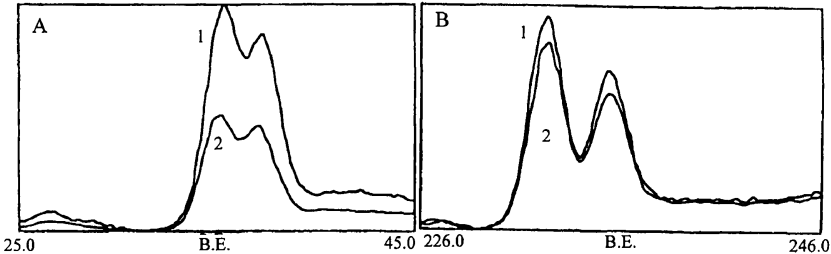

Figure 2. W(4f) (A) and Mo(3d) (B) XPS spectra of PAN doped by $\mathrm{SiW}_{11} \mathrm{~V}$ and $\mathrm{SiMo}_{11} \mathrm{~V}$ in a one-step method (1) and two-step method (2).

step method. The reason might be that the species with one-step method have also enclosed charged nitrogens, resulting from undesired side reactions, crosslinking and branching. Doping way is very important for properties of materials.

XPS spectra of W(or Mo) in the samples are similar. Figure 2 shows the $\mathrm{Mo}_{3 \mathrm{~d}}$ doublet obtained for $\mathrm{S}_{3}$ comprising peaks at 235.6 and $232.5 \mathrm{eV}$, and the $\mathrm{W}_{4 \mathrm{f}}$ doublet obtained for $\mathrm{S}_{1}$ comprising peaks at 35.4 and $37.3 \mathrm{eV}$. The spectrum can be fitted with only one doublet due to $\mathrm{Mo}_{3 \mathrm{~d} 5 / 2}, \mathrm{Mo}_{3 \mathrm{~d} 3 / 2}$, and $\mathrm{W}_{4 \mathrm{f} 7 / 2}, \mathrm{~W}_{4 \mathrm{f} 5 / 2}$ transitions. Chemical shifts are typical of $\mathrm{Mo}(\mathrm{VI})$ and $\mathrm{W}(\mathrm{VI})$. Therefore no Mo or $\mathrm{W}$ is present in oxidation lower than +6 in the above samples. ${ }^{17}$ XPS spectra of W(or Mo) indicated that the polyacid still kept their structure after synthesis and purification processes.

\section{XRD Spectra}

X-Ray diffraction patterns of the polyanilines prepared in the presence of HPA are the same in Figure 3. There is a sharp peak at $d=12.3 \AA$ close to the polymer repeat distance ${ }^{18}$ and two very broad overlapping halos in the samples in the one-step method. PAN protonation with simple inorganic acids such as, for example, $\mathrm{HCl}$ leads to a more ordered structure with relatively distinct Bragg reflections. ${ }^{19}$ The X-Ray diffraction patterns of doping PAN with the preparation method (one-step or 


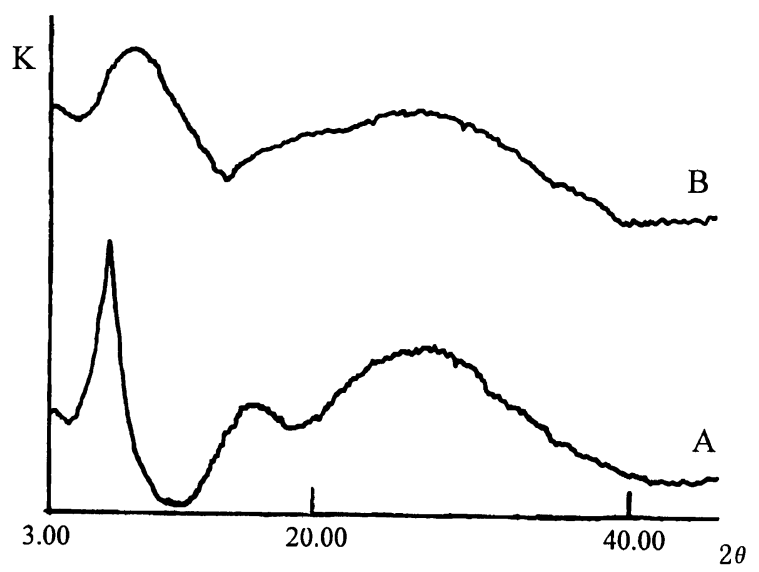

Figure 3. XRD of PAN doped with $\mathrm{SiW}_{11} \mathrm{~V}$ in one-step (A) and two-step (B) method.

two-step) are very similar and give no indication of a crystalline phase. However, comparing with the one-step method, we can also find that the sharp peak at $d=12.3$ $\AA$ become passive in samples by two-step method. This indicates that the molecule order of the samples became weak from one-step to two-step method. ${ }^{20}$ No peaks from any crystalline form of heteropoly acid can be observed indicating that Keggin units are inserted into the polymer matrix. ${ }^{15}$

\section{Conductivity}

A polyaniline base is insulating with the conductivity of the order of $10^{-12} \mathrm{~S} \mathrm{~cm}^{-1}$, and its protonation gives rise to increase of electronic conductivity by several orders of magnitude. ${ }^{20}$ The conductivity of polyaniline doped with HPA is usually $10^{-3}-10^{-6} \mathrm{~S} \mathrm{~cm}^{-1}$. Here the conductivity of polyaniline doped with vanadium-containing HPA is higher than before, i.e., $\mathrm{S}_{1}: 2.07 \times 10^{-1}$, $\mathrm{S}_{2}: 2.50 \times 10^{-2}, \quad \mathrm{~S}_{3}: 1.26 \times 10^{-2}, \quad \mathrm{~S}_{4}: 6.14 \times 10^{-1}, \quad \mathrm{~S}_{1}{ }^{\prime}:$ $7.03 \times 10^{-5}, \mathrm{~S}_{2}{ }^{\prime}: 1.06 \times 10^{-3}, \mathrm{~S}_{3}{ }^{\prime}: 6.16 \times 10^{-4}, \mathrm{~S}_{4}{ }^{\prime}: 1.25$ $\times 10^{-3} \mathrm{~S} \mathrm{~cm}^{-1}$. This indicates that the one-step procedure has higher conductivity than the two-step procedure.

Polyaniline in the form of polyleucoemeraldine can be oxidatively doped by withdrawal of electrons from its $\pi$ bonds. Two approaches to "doping" can be used: 1. HPA can be incorporated into the growing polymeric matrix during electrochemical or chemical polymerization of a suitable monomer. In this case growing polymer chains are cationic and the inserted HPA serves as chargecompensating species. 2. HPA can be incorporated into the polymer matrix via the so-called doping reaction. In this case polymer matrix formation and the incorporation of HPA into this matrix are separated in time. HPA is introduced into the already formed, neutral solid polymer. The doping consists therefore of transformation of neutral polymer chains into polycations and the simultaneous incorporation of HPA. This doping can be oxidative in acid-base.

The doping of polyaniline is different from other conjugated conducting polymers, polyaniline base can be doped to a conducting form without changing the number of $\pi$-electrons thought protonation by exposure to an appropriate protonic acid in aqueous solution. PAN of
Table IV. Results of elemental analysis (\%)

\begin{tabular}{|c|c|c|c|c|}
\hline Empirical formula & $\mathrm{C}$ & $\mathrm{H}$ & $\mathrm{N}$ & W \\
\hline $\mathrm{C}_{6} \mathrm{H}_{4.5} \mathrm{~N}\left(\mathrm{SiW}_{11} \mathrm{~V}\right)_{0.042}{ }^{\mathrm{a}}$ & 35.01 & 2.40 & 6.73 & 41.29 \\
\hline $\mathrm{C}_{6} \mathrm{H}_{45}^{4.5} \mathrm{~N}\left(\mathrm{SiW}_{11} \mathrm{~V}\right)_{0.066}{ }^{a}$ & 26.50 & 1.94 & 5.22 & 49.11 \\
\hline $\mathrm{C}_{6} \mathrm{H}_{4.5} \mathrm{~N}\left(\mathrm{SiW}_{11} \mathrm{~V}\right)_{0.106}{ }^{\mathrm{a}}$ & 18.35 & 1.47 & 3.61 & 55.58 \\
\hline $\mathrm{C}_{6} \mathrm{H}_{4.5} \mathrm{~N}\left(\mathrm{SiW}_{11} \mathrm{~V}\right)_{0.142}{ }^{\mathrm{a}}$ & 14.99 & 1.42 & 2.94 & 59.76 \\
\hline $\mathrm{C}_{6} \mathrm{H}_{4.5} \mathrm{~N}\left(\mathrm{SiW}_{11} \mathrm{~V}\right)_{0.161} \mathrm{a}$ & 13.51 & 1.27 & 2.71 & 61.12 \\
\hline $\mathrm{C}_{6} \mathrm{H}_{4.5} \mathrm{~N}\left(\mathrm{SiW}_{11} \mathrm{~V}\right)_{0.008}$ & 64.02 & 4.33 & 12.47 & 14.38 \\
\hline $\mathrm{C}_{6} \mathrm{H}_{4.5} \mathrm{~N}\left(\mathrm{SiW}_{11} \mathrm{~V}\right)_{0.024} \mathrm{~b}$ & 45.86 & 3.97 & 8.61 & 31.17 \\
\hline $\mathrm{C}_{6} \mathrm{H}_{4.5} \mathrm{~N}\left(\mathrm{SiW}_{11} \mathrm{~V}\right)_{0.031}^{\mathrm{b}}$ & 41.00 & 2.90 & 8.03 & 35.70 \\
\hline $\mathrm{C}_{6} \mathrm{H}_{4.5} \mathrm{~N}\left(\mathrm{SiW}_{11} \mathrm{~V}\right)_{0.074} \mathrm{~b}$ & 24.51 & 1.77 & 4.91 & 50.94 \\
\hline $\mathrm{C}_{6} \mathrm{H}_{4.5} \mathrm{~N}\left(\mathrm{SiW}_{11} \mathrm{~V}\right)_{0.097}$ & 20.18 & 1.54 & 4.01 & 54.96 \\
\hline
\end{tabular}

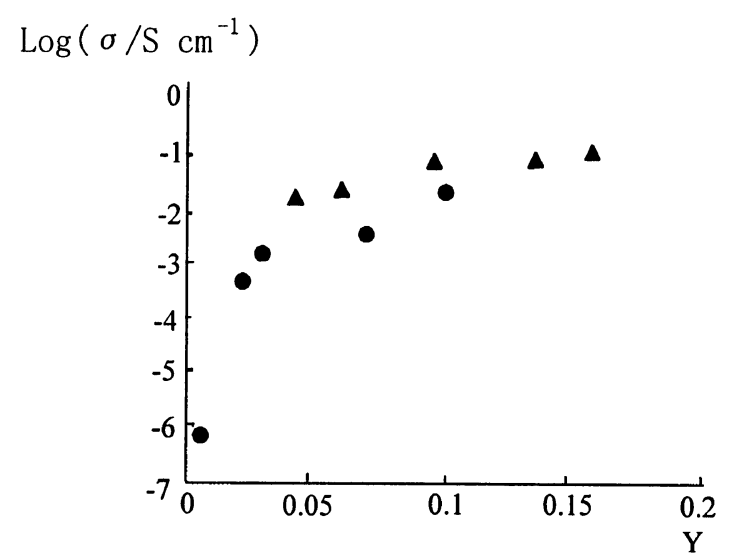

Figure 4. Conductivity vs. HPA content (y) in the materials $\left(\mathrm{C}_{6} \mathrm{H}_{4.5} \mathrm{~N}\right)\left(\mathrm{SiW}_{11} \mathrm{~V}\right)_{y}$ : $\Delta$ one-step method; 1 two-step method.

ideal emeraldine base form contains alternating amine and imine repeat units. When emeraldine base is doped by a protonic acid, protonation occurs at imine nitrogen sites to yield polysemiquinone, in which the polarons delocalize along the chain. ${ }^{6}$ Heteropolyacid is a stronger protonic acid, and PAN doped with HPA may have the same conducting mechanism. We think that the doping in the two-step method is necessarily connected with chemisorption of HPA at the surface of PAN and HPA may not be evenly distributed throughout the whole volume of PAN. The protonated phase is limited to the surface and the rate of its penetration into the bulk of PAN is lower, so the conductivity is lower.

Since the conductivity of polyaniline depends on water vapour pressure in air, ${ }^{10}$ all samples were dried under vacuum $40^{\circ} \mathrm{C}$ for $48 \mathrm{~h}$. We think that there is no water or other solvents in the polymers.

To investigate the effects of different doping degrees on conductivity, we synthesized materials that had different doping degrees by the one-step and two-step methods. $\mathrm{H}_{5} \mathrm{SiW}_{11} \mathrm{VO}_{40}$ as dopant, the method of synthesis is the same as before, but $\mathrm{H}_{5} \mathrm{SiW}_{11} \mathrm{VO}_{40}$ was $4,7,10$, 12 , and $14 \mathrm{mmol}$ with one-step method and 1.1, 1.8, 2.9, 3.6 , and $5.5 \mathrm{mmol}$ with the two-step method. To show the degree of doping directly, we change the empirical formula to $\left(\mathrm{C}_{6} \mathrm{H}_{4.5} \mathrm{~N}\right)\left(\mathrm{SiW}_{11} \mathrm{~V}\right)_{y}$, so the number of $y$ shows the number of HPA which have been doped. The results of elemental analysis are shown in Table IV.

Conductivity of above materials at room temperature is shown in Figure 4. Figure 4 indicates that conductivity increases with the doping at the beginning and the 
Chemical Syntheses of the Conducting Polyaniline Material

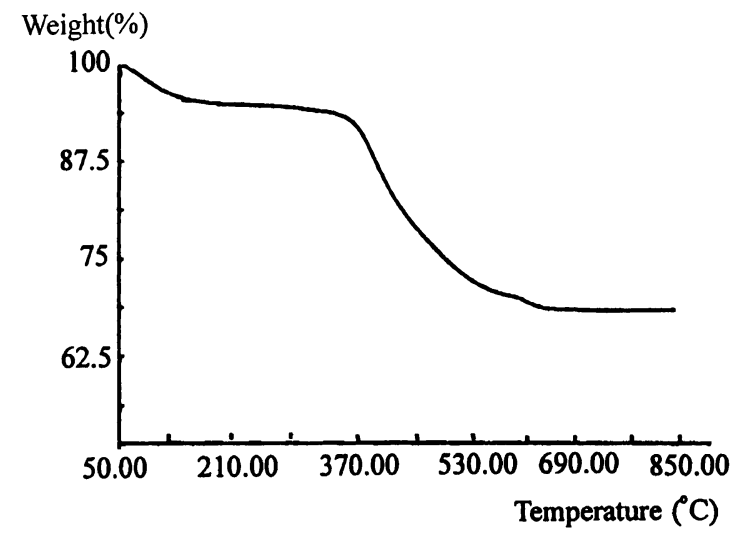

Figure 5. $\mathrm{TG}$ of $\mathrm{C}_{6} \mathrm{H}_{4.5} \mathrm{~N}\left(\mathrm{SiW}_{11} \mathrm{~V}\right)_{0.106}$.

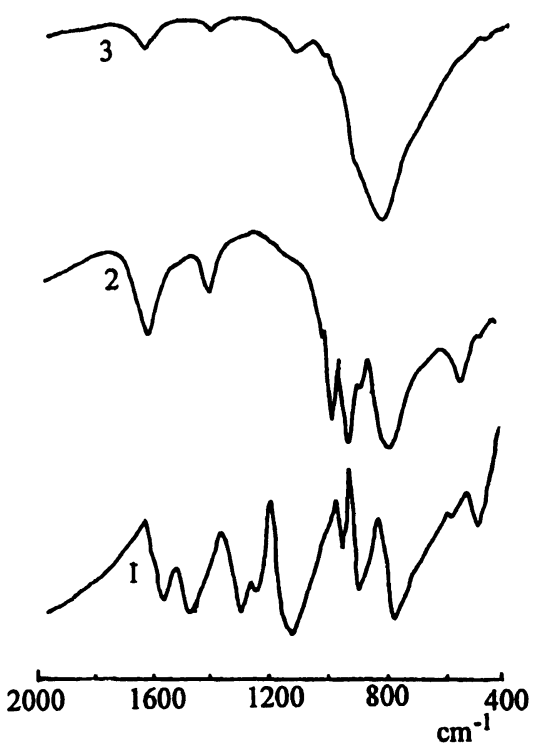

Figure 6. IR spectra of $\mathrm{C}_{6} \mathrm{H}_{4.5} \mathrm{~N}\left(\mathrm{SiW}_{11} \mathrm{~V}\right)_{0.106}$ treated by heating at different temperature. $1,210^{\circ} \mathrm{C} ; 2,450^{\circ} \mathrm{C} ; 3,620^{\circ} \mathrm{C}$.

rate of conductivity is faster with the two-step method than with the one-step method. However conductivity may not increase with doping when doping is in a certain range.

The conductivity of materials descended when the materials were heated. Figure 5 shows the thermogravimetric measurements in nitrogen atmosphere of the $\mathrm{C}_{6} \mathrm{H}_{4.5} \mathrm{~N}\left(\mathrm{SiW}_{11} \mathrm{~V}\right)_{0.106}$. This polymer shows weight loss starting before $140^{\circ} \mathrm{C}$. This is the loss of absorbed and crystal water. Weight of the material keeps relatively stable between $140^{\circ} \mathrm{C}$ and $360^{\circ} \mathrm{C}$. The material is thus not degradated during $140-360^{\circ} \mathrm{C}$. Sharp degradation followed by a majority weight loss at beginning of about $450^{\circ} \mathrm{C}$.

The majority weight loss at beginning of about $450^{\circ} \mathrm{C}$ is due to degradation of polymer backbone as indicated by the IR spectrum of material heated at $450^{\circ} \mathrm{C}$ for 60 min (see Figure 6). However, HPA at $450^{\circ} \mathrm{C}$ keeps its Keggin structure. The material degrades completely at $620^{\circ} \mathrm{C}$ (Figure 6). The effect of thermal treatment on the conductivity of $\mathrm{C}_{6} \mathrm{H}_{4.5} \mathrm{~N}\left(\mathrm{SiW}_{11} \mathrm{~V}\right)_{0.106}$ is shown in Figure 7.

Polym. J., Vol. 33, No. 5, 2001

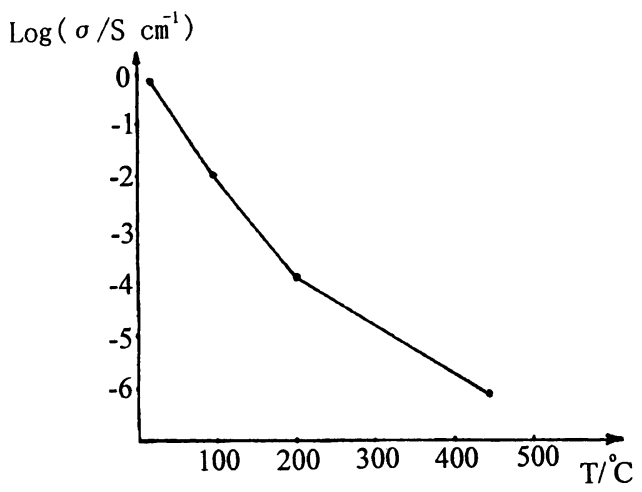

Figure 7. Effects of thermal treatment on the conductivity of $\mathrm{C}_{6} \mathrm{H}_{4.5} \mathrm{~N}\left(\mathrm{SiW}_{11} \mathrm{~V}\right)_{0.106}$.

As shown in Figure 7, the conductivity of $\mathrm{C}_{6} \mathrm{H}_{4.5} \mathrm{~N}$ $\left(\mathrm{SiW}_{11} \mathrm{~V}\right)_{0.106}$ decreased when the material was heated. Compared with IR spectra and thermogravimetric curve of $\mathrm{C}_{6} \mathrm{H}_{4.5} \mathrm{~N}\left(\mathrm{SiW}_{11} \mathrm{~V}\right)_{0.106}$ treated by heating at different temperatures, the material was not degrated before $360^{\circ} \mathrm{C}$, but the conductivity of the material decrease with treatment of heating. This suggests that the conductivity decreases below $360^{\circ} \mathrm{C}$ for $\mathrm{C}_{6} \mathrm{H}_{4.5} \mathrm{~N}\left(\mathrm{SiW}_{11} \mathrm{~V}\right)_{0.106}$ studied in this work is not due to the elimination or decomposition of the HPA and it is also not due to the decomposition of the PAN. The conductivity decrease may thus be due to change in the arrangement of polyaniline or chemical reactions between HPA and PAN.

Acknowledgment. This work was supported by National Natural Science Foundation of China.

\section{REFERENCES}

1. P. M. Borsenberger and W. T. Gruenbaum, J. Polym. Sci., Part B: Polym. Phys., 34, 575 (1996)

2. D. E. Katsoulis, Chem. Rev., 98, 359 (1998).

3. J. Gong, Z.-M. Su, R.-S. Wang, and L.-Y. Qu, MRS 1999 Spring Meeting, San Francisco, CA., p 462.

4. J. Gong, S.-G. Wang, Z.-W. Xie, H. He, Z.-M. Dai, and L.-Y. $\mathrm{Qu}$, The 7th National Conference on Inorganic Solid State Chemistry and Synthesis Chemistry, P. R. China, 2000, p 64.

5. M. Lira-Cantu, P. Gomez-Romero, Chem. Mater., 10, 698 (1998).

6. A. G. MacDiarmid and A. J. Epstein, Faraday Disc. Chem. Soc., 88, 317 (1989).

7. E. M. Genies, A. Boyle, M. Lapkowski, and C. Tsintavis, Synth. Met., 36, 139 (1990).

8. M. Lapkowski, W. Turek, M. Barth, and S. Lefrant, Synth. Met., 69, 127 (1995).

9. M. Hasik, W. Turek, E. Stochmal, M. Lapkowski, and A. Pron, J. Catal., 150, 544 (1994).

10. M. Hasik, A. Pron, J. Pozniczek, A. Bielanski, Z. Piwowarska, K. Kruozalz, and R. Dziembaj, J. Chem. Soc. Faraday Trans., 90, 2099 (1994).

11. X. Xie, M. Guo, "Base of Materiaos Science", Beijing University of Aeronautics and Astronautics Press, Beijing, 1999.

12. P. J. Domaille, J. Am. Chem. Soc., 106, 7677 (1984).

13. G. A. Tsigdinos and C. J. Hallada, Inorg. Chem., 7, 437 (1968).

14. G. W. Hwang, K.-Y. Wu, M.-Y. Hua, H.-T. Lee, and S. A. Chen, Synth. Met., 92, 39 (1998)

15. L.-Y. Qu, R.-Q. Lu, J. Peng, Y.-G. Chen, and Z.-M. Dai, Synth. Met., 84, 135 (1997).

16. J. Gong, Z.-M. Su, Z.-M. Dai, R.-S. Wang, and L.-Y. Qu, 
Synth. Met., 101, 751 (1999).

17. M. Hasik, A. Pron, I. K. Bajer, J. Pozniczek, A. Bielanski, Z. Piwowarska, and R. Dziembaj, Synth. Met., 55-57, 972 (1993).

18. P. Adam, Synth. Met., 46, 277 (1992).
19. J. P. Pouget, M. E. Jozefowicz, A. J. Epstein, X. Tang, and A. G. MacDiarmid, Macromolecules, 24, 779 (1991).

20. C. O. Yoon, M. Reghu, and A. J. Heeger, Synth. Met., 75, 229 (1995). 